\title{
PENINJAUAN K3 PADA PROYEK PEMBANGUNAN JALAN BETON,DRAINASE, PLAT DUECKER, BAK SAMPAH(TPS),DAN PENATAAN JALAN KECAMATAN WARA BARAT, KOTA PALOPO
}
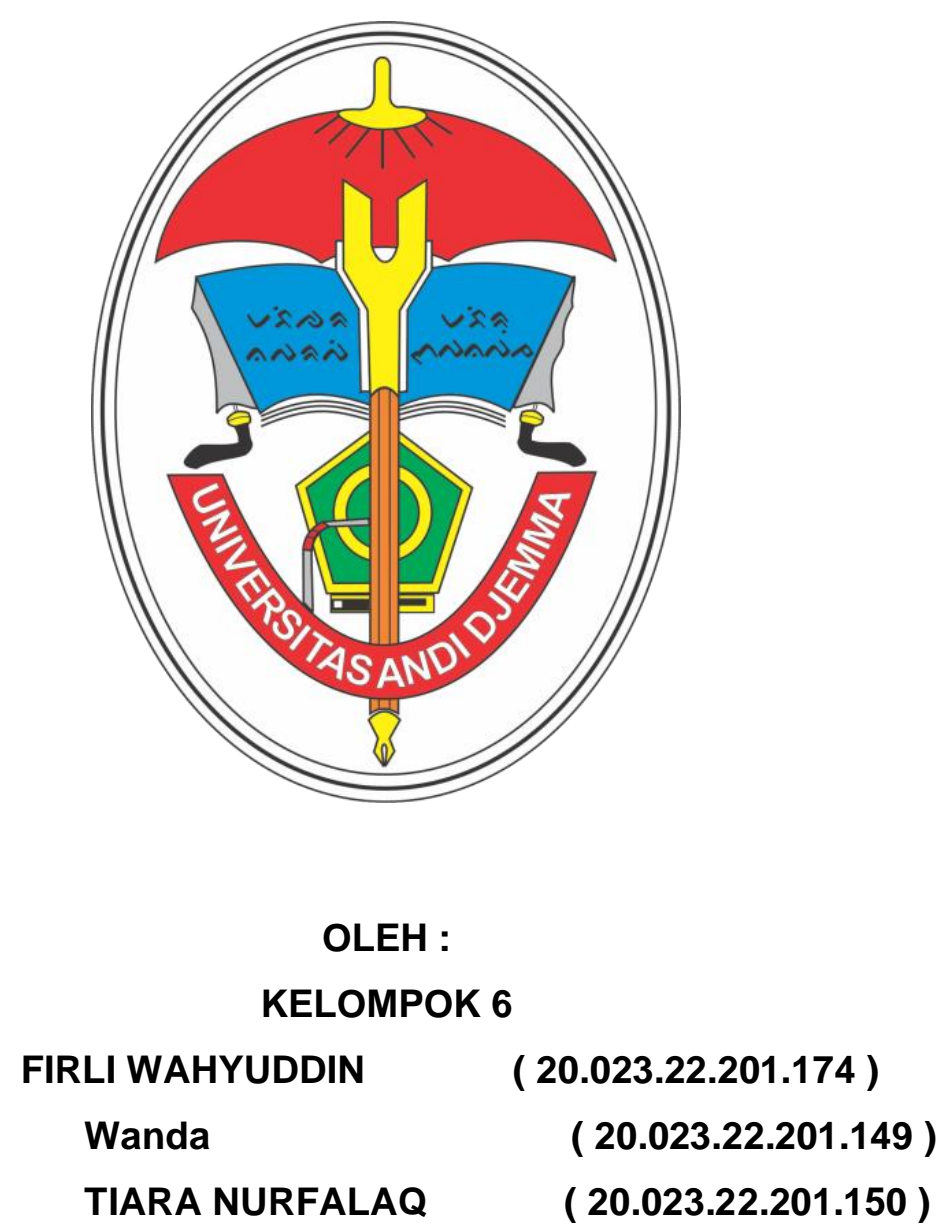

FAKULTAS TEKNIK JURUSAN SIPIL UNIVERSITAS ANDI DJEMMA 


\section{KATA PENGANTAR}

Puji dan syukur kita panjatkan kepada Tuhan Yang Maha Esa. Karena, berkat limpahan dan rahmat-Nya, kami selaku penyusun dapat menyelesaikan laporan hasil peninjauan $\mathrm{k} 3$ ini guna mengetahui sebagai pembelajaran dan untuk memenuhi tugas mata kuliah K3 \& UU Perburuan. Laporan ini dibuat sebagai laporan pertanggung jawaban terhadap peninjaun proyek selama 2 (Dua) minggu selama berada di lokasi proyek.

Kami menyadari bahwa laporan ini masih banyak kekurangan dan jauh dari kata sempurna. Untuk itu, kepada dosen pembimbing kami meminta masukannya demi perbaikan laporan hasil peninjauan K3 yang lebih baik dan mengharapkan kritik serta saran yang membangun dari para pembaca.

Akhir kata kami selaku penyusun mengucapkan terimakasih.

Palopo, 30 Juli 2021

Penyusun

\section{DAFTAR ISI}





DAFTAR ISI .................................................................................................

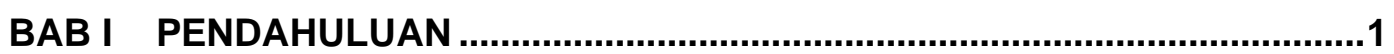

$1.1 \quad$ Latar Belakang .....................................................................

1.2 Maksud dan Tujuan ............................................................. 1



BAB II TINJAUAN TEORI DAN REGULASI .................................................3

2.1 Tinjauan Umum .....................................................................

2.2 Ruang Lingkup K3 Proyek Konstruksi .......................................

BAB III PEMBAHASAN ...............................................................................6

Informasi Proyek ................................................................... 
3.2 Item-item Pekerjaan Konstruksi Proyek...................................... 6

3.3 Hasil Observasi ................................................................. 6

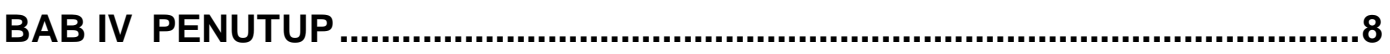

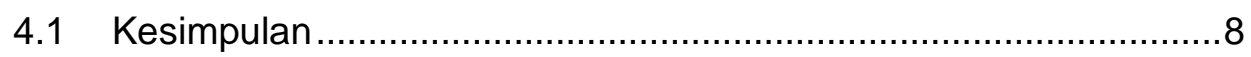



DAFTAR PUSTAKA .......................................................................................... 


\section{BAB I \\ PENDAHULUAN}

\subsection{Latar Belakang}

Kesehatan dan Keselamatan Kerja (K3) merupakan upaya kita untuk menciptakan lingkungan kerja yang sehat dan aman, sehingga dapat mengurangi probabilitas kecelakaan kerja / penyakit akibat kelalaian yang mengakibatkan demotivasi dan dan defisiensi produktivitas kerja. Menurut UU Pokok Kesehatan RI No. 9 Th. 1960 Bab I Pasal II, Kesehatan Kerja adalah suatu kondisi Kesehatan yang bertujuan agar masyarakat pekerja memperoleh derajat Kesehatan setinggi-tingginya, baik jasmani ,rohani maupun social, dengan usaha pencegahan dan pengobatan terhadap penyakit atau gangguan Kesehatan yang disebabkan oleh pekerjaan dan lingkungan kerja maupun penyakit umum.

Keselamatan dan kesehatan kerja (K3) merupakan salah satu faktor penting yang dapat mempengaruhi produktivitas karyawan. Resiko kecelakaan serta penyakit akibat kerja sering terjadi karena program K3 tidak berjalan dengan baik. Hal ini dapat berdampak pada tingkat produktivitas karyawan. Pada umumnya kecelakaan kerja disebabkan oleh dua faktor yaitu manusia dan lingkungan. Faktor manusia yaitu tindakan tidak aman dari manusia seperti sengaja melanggar peraturan keselamatan kerja yang diwajibkan atau kurang terampilnya pekerja itu sendiri. Sedangkan faktor lingkungan yaitu keadaan tidak aman dari lingkungan kerja yang menyangkut antara lain peralatan atau mesin-mesin.

\subsection{Maksud dan Tujuan}

Kuliah Lapangan ini dilakukan guna mengetahui permasalahan yang terjadi pada saat pembangunan drainase kabupaten Luwu Timur, sehingga dapat diketahui resiko apa saja yang terjadi pada saat pembangunan. Kemudian dapat ditentukan solusi yang tepat untuk mengatasi permasalahan yang ada.

1. Mengidentifikasi faktor-faktor risiko terhadap pelaksanaan pembangunan drainase kabupaten Luwu Timur.

2. Mengetahui Penerapan Sistem Manajemen Keselamatan dan Kesehatan Kerja (SMK3) pada proyek ini. 
3. Mengetahui risikoyang paling dominan terjadi selama pelaksanaan pembangunan drainase kabupaten Luwu Timur.

\subsection{Manfaat}

Dengan adanya laporan kuliah lapangan ini, diharapkan dapat menambah wawasan para pembaca agar lebih memperhatikan keselamatan dan Kesehatan kerja dalam dunia kerja, dan juga dapat digunakan sebagai referensi bagi penulis lain yang berhubungan dengan $\mathrm{K} 3$. 


\section{BAB II TINJAUAN TEORI DAN REGULASI}

\subsection{Tinjauan Umum}

Keselamatan dan Kesehatan Kerja Konstruksi yang selanjutnya disebut K3 Konstruksi adalah segala kegiatan untuk menjamin dan melindungi keselamatan dan kesehatan tenaga kerja melalui upaya pencegahan kecelakaan kerja dan penyakit akibat kerja pada pekerjaan konstruksi.

Menurut UU Pokok Kesehatan RI No. 9 Th. 1960 Bab I Pasal II, Kesehatan Kerja adalah suatu kondisi Kesehatan yang bertujuan agar masyarakat pekerja memperoleh derajat Kesehatan setinggi-tingginya, baik jasmani ,rohani maupun social, dengan usaha pencegahan dan pengobatan terhadap penyakit atau gangguan Kesehatan yang disebabkan oleh pekerjaan dan lingkungan kerja maupun penyakit umum.

Menurut H. W Heinrich dalam Notoadmodjo (2007), penyebab keselamatan kerja yang sering ditemui adalah perilaku yang tidak aman sebesar $88 \%$ dan kondisi lingkungan yang tidak aman sebesar $10 \%$, atau kedual hal tersebut terjadi secara bersamaan.

Berdasarkan UU No. 1 Tahun 1970 tentang keselamatan kerja , bahwa tujuan Kesehatan dan Keselamatan Kerja yang berkaitan dengan mesin, peralatan, landasan tempat kerja dan lingkungan tempat kerja adalah mencegah terjadinya kecelakaan dan sakit akibat kerja, memberikan perlindungan pada sumber-sumber produksi sehingga dapat meningkatkan efiensi dan produktivitas.

\subsection{Ruang Lingkup K3 Proyek Konstruksi}

Dunia proyek merupakan salah satu sektor lapangan kerja tertinggi yang sering terjadinya kecelakan kerja. Oleh sebab itu, untuk mencegah terjadinya kecelakaan kerja di proyek diperlukan beberapu Alat Pelindung Diri (APD) yang disediakan bagi tenaga kerja proyek (Kuli Bangunan). Alat Pelindung Diri (APD) adılah suatu alat yang mempunyai kemampuan untuk melindungi seseorang yang fungsinya mengisolasi sehagiun atau seluruh tubuh dari potensi bahaya di tempat kerja.

Keselamatan dan Kesehatan Kerja (K3) adalah semua kondisi dan faktor yang dapat berdampak pada keselamatan dan kesehatan kerja tenaga kerja 
maupun orang lain (kontraktor, pemasok, pengunjung dan tamu) tempat kerja. Penerapan prinsip K3 di proyek sangat perlu diperhatikan dalam pekerjaan konstruksi. Pelaksana konstruksi harus mengetahui dan menerapkan prinsipprinsip kerja sesuai ketentuan K3 di lingkungan proyek.

\subsubsection{Kelengkapan Administrasi K3}

Setiap pelaksanaan pekerjaan kontruksi wajib memenuhi kelengkapan adminitrasi K3, meliputi :

1. Pendaftaran proyek ke departemen tenaga kerja setempat

2. Pendaftaran dan pembayaran asuransi tenaga kerja ( Astek )

\subsubsection{Penyusunan Safety Plan}

Safety Plan adalah rencana pelaksanaan K3 untuk proyek yang bertujuan agar dalam pelaksanaan nantinya proyek akan aman dari kecelakaan sehingga menghasilkan pnduktivitas kerja yang tinggi. Safety Plan berisi :

1. Pembukaan yang berisi (gambaran proyek dan pokok perhitungan untuk kegiatan K3)

2. Resiko kecelakaan dan pencengahannya

3. Tata cara pengoperasian peralatan

4. Alamat Instansi terkait seperti (Rumah sakit, kantor Polisi, Depnaker dan Dinas kebakaran).

\subsubsection{Perlengkapan K3 dalam Konstruksi}

1. Safety Helmet

Safety helmet berfungsi sebagai pelindung kepala dari benda yang mengenai kepala secara langsung.

2. Safety Belt

Safety belt berfungsi sebagai pelindung diri ketika pekerja bekerja berada di atas ketinggian.

3. Safety Shoes

Safety shoes berfungsi untuk mencegah kecelakaan fatal yang menimpa kaki karena benda tajam utau berat, benda panas, cairan kimia dan sebagainya.

4. Sepatu Karet

Sepatu karet (sepatu boot) adalah sepatu yang didesain khusus untuk pekerja yang berada di area basah (becek atau 
berlumpur). Kebanyakan sepatu karet di lapisi dengan metal untuk melindungi kaki dari benda tajam atau berat, benda panus, cairan kimia, dsb.

5. Sarung Tangan

Berfungsi sebagai alat pe indung tangan pada saat bekerja di tempat atau situasi yang dapat mengakibatkan eedera tangan. Bahan dan bentuk sarung tangan disesuaikan dengan fungsi masing-masing pekerjaan.

6. Masker

Masker dapat berfungsi sebagai pelindung hidung dan penyaring udara yang dihirup suaat bekerja ditempat yang meiliki kualitas udara buruk (missal berdebu, beracun, dsb)

7. Tali pengaman

Pada pekerjaan yang berada diketinggian, sangat memerlukan alat pelindung diri berupa tali pengaman ( safety hamess. Alat pelindung diri ini digunakan jika bekerjaa pada ketinggian lebih dari 1,8 meter. Hal ini akan melindungi pekerjaan agar terhibur dari potensi jatuh dari ketinggian.

8. Kaca Mata

Pada pekerjaan pengelasan maupun pekerjauan permesinan perlu menggunakan pelindung mata. Hal ini untuk me lindung mata dari percikan api ataupun serpihan dari besi yang mengalami proses pengerjaan pemersinan,

9. Pelindung Wajah

Berfungsi sebagi pelindung wajah dari perikan benda asing saat bekerja (missal pekerjaan menggerinda). 


\section{BAB III \\ PEMBAHASAN}

\subsection{Informasi Proyek}

Berikut uraian hasil monitoring dan evaluasi pelaksanaan K3 Di kecamatan wara barat, kota palopo tanggal 30 Juli 2021, yaitu :

Lokasi Kegiatan/proyek :KELURAHAN TAMARUNDUNG, KECAMATAN WARA BARAT, KOTA PALOPO

Nama Proyek :BKM TAMARUNDUNG IDAMAN

Nilai Proyek

:Rp.1.068.449.000, -

Jumlah Pekerja

: 36 Orang

Sumber \& Tahun Anggaran

Lama Pekerjaan

:BPM DAN SWADAYA MASYARAKAT Tahun 2021

Pelaksana Kegiatan :120 HARI

:KSM SEJAHTERA 


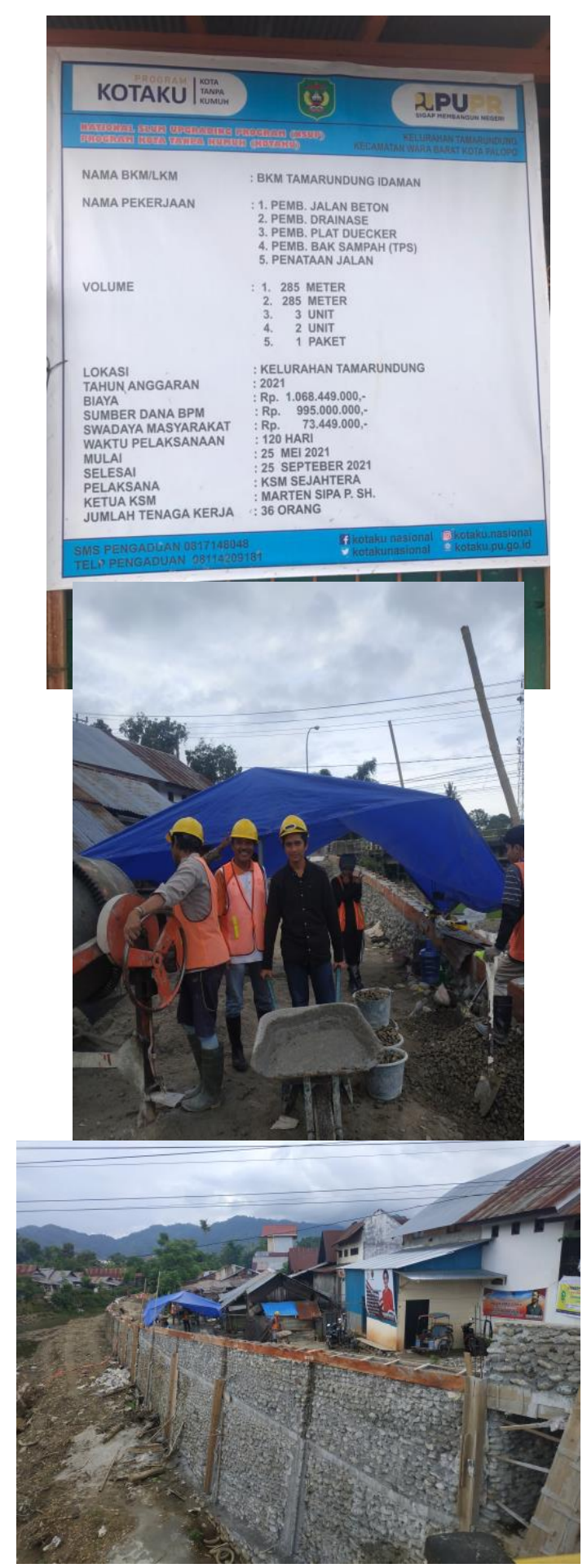

\subsection{Item-item Pekerjaan Konstruksi Proyek}

Secara garis besar konstruksi yang digunakan dalam pembangunan drainase diatas antara lain:

- Galian

- Pemasangan Batu 
- Mata Sapi

- Plasteran Topi

\subsection{Hasil Observasi}

Hasil Observasi pada tinjauan pada pembangunan jalan beton,drainase, plat duecker, bak sampah(TPS),Dan penataan jalan. Keselamatan Kerja atau K3 belum dijalankan dengan baik. Terlihat bahwa para pekerja sebagian besar tidak memakai Alat Pelindung Diri (APD), dan hanya beberapa pekerja saja yang memakai Alat Pelindung berupa sepatu karet, masker, dan sarung tangan.

Dalam pekerjaan pembangunan jalan beton,drainase, plat duecker, bak sampah(TPS),Dan penataan jalan. drainase diutamakan memakai atritut K3 agar menghindari dari kejadian-kejadian yang tidak diinginkan. Keselamatan kesehatan kerja (K3) yang diterapkan pada pekerjaan drainase belum dijalankan dengan baik. Seharusnya pekerja itu diberi Alat Pelindung Diri (APD) untuk melindungi dirinya dari bahaya-bahaya pada saat proses pengerjaan drainase berlangsung. 


\section{BAB IV \\ PENUTUP}

\subsection{Kesimpulan}

Pelaksanaan Kesehatan dan Keselamatan Kerja (K3) adalah salah satu bentuk upaya untuk menciptakan tempat kerja yang aman, sehat, bebas dari pencemaran lingkungan, sehingga dapat mengurangi dan atau bebas dari kecelakaan kerja dan penyakit akibat kerja yang pada akhimya dapat meningkatkan efisiensi dan produktivitas kerja.

Kecelakaan kerja tidak saja menimbulkan korban jiwa maupun kerugian materi bagi pekerja dan pengusaha, tetapi juga dapat mengganggu proses produksi secara menyeluruh, merusak lingkungan yang pada akhirnya akan berdampak pada masyarakat luas.

Pada dasarnya UU Keselamatan Kerja yang digunakan untuk mencegah terjadinya kecelakaan kerja, menjamin suatu proses produksi berjalan teratur dan sesuai rencana, dan mengatur agar proses produksi berjalan teratur dan sesuai rencana, dan mengatur agar proses produksi tidak merugikan semua pihak. Setiap tenaga kerja berhuk mendapatkan perlindungan keselamatan dalam melakukan pekerjaannya untuk kesejahteraan dan meningkatkan produksi serta produktivitas nasional. Dan dari hasil survey penulis menunjukkan bahwa perlu adanya peningkatan pengetahuan, kesadaran, dan sikap yang mundukung akan pentingnya pemakaian Alat Pelindung Diri (APD) pada waktu melakukan pembangunan drainase.

Dari hasil Analisa Resiko Sistem Manajemen Kesehatan dan keselamatan kerja Pada Pelaksanaan pembangunan drainase di Luwu Timur ini maka dapat diperoleh kesimpulan sebagai berikut :

1. Faktor resiko sebagai dampak tidak diterapkan sistem manajemen kesehatan dan keselamatan kerja pada proyek pembangunan Drainase Luwu Timur.

2. Berdasarkan pelaksanaanya Faktor resiko sebagai dampak tidak diterapkan sistem manajemen kesehatan dan keselamatan kerja, Dari segi resiko pekerjaan masih kurang kesadaran dari para pekerja dalam memperhatikan resiko kecelakan kerja di proyek. 


\subsection{Saran}

1. Mempertahankan dan meningkatkan penerapan Sistem Manjemen Kesehatan dan Keselamatan Kerja yang telah berjalan dilokasi proyek.

2. Peningkatan intensitif terhaap pekerja di lingkungan proyek untuk memacu kebiasan yang aman, misalnya, dengan pemberian penghargaan kepada pekerja dalam hal pemakaian APD dan ketaatan dalam mematuhi peraturan K3 serta dikenakan sangsi untuk segala pelanggaran aturan.

3. Dibutuhkannya campur tanagn pemerintah sebagai pengontrol dan pemberi sanksi bagi perusahan yang mengabaikan masalah sistem manajemen kesehatan dan keselamatan kerja sehingga menimbulkan perhatian dan kesadaran dari pihak perusahaan maupun pekerja untuk menerapkan sistem manajemen kesehatan dan keselamatan kerja tersebut sehingga sangat penting dibutuhkannya campur tangan pemerintah. 


\section{DAFTAR PUSTAKA}

[1] Anonim.2008.ManajemenRisikokesehatandankeselamatankerja./200 8/01/manajemen-risiko-untuk-k3.

[2] Anonim.2009.DefinisidanManfaatPenerapanManajemenRisikojurnals dm.blogspot.com/2009/09.

[3] Ariagusti.2011.ManajemenRisikoDalamKeselamatan\&KesehatanKerj a.ariagusti.w ordpress.com/2011/01/07/.

[4] Ariagusti.2011.ManajemenRisikoK3diPerusahaan.BlogDosenKesehat anMasyaraka t.html.

[5] Ishak,Aulia.2004.ManajemenK3DalamUpayaMeningkatkanProduktivit asKerja.repository.usu.ac.id/bitstream/123456789/1458/1/industriulia 3.

[6] Mansyur,Muchtaruddin.2007.ManajemenRisikoKesehatanDiTempatK erja.docs.goo gle.com/viewer?a=v\&q=cache:InJ_9_qznQIJ:indonesia.

[7] Mulyadi,HendraDicky.2011.ManajemenRisiko.dickyhendramulyadi@y ahoo.com

[8] Rachmadi.2011.ManajemenResiko(JanganTakutDenganResiko).sho wthread.php?ti $d=16221$.

[9] Marzaman, L. U., Hafid, Z., Fisu, A. A., \& Nurhijrah, N. (2021). Planning Concept of Lalebbata: Combining Heritage, Policy and Participation. PENA TEKNIK: Jurnal IImiah IImu-IImu Teknik, 6(1), 3947.

[10] Fisu, A. A. (2016). Potensi Demand Terhadap pengembangan Kanal Jongaya \& Panampu Sebagai Moda Transportasi (Waterway) di Kota Makassar. Jurnal Manajemen Transportasi \& Logistik, 3(3), 285-298.

[11] Tresidder, J. O., POWELL, T., MEYERS, D., \& BURRELL, J. (1968). THE LONDON TRANSPORTATION STUDY: METHODS AND TECHNIQUES. Proceedings of the Institution of Civil Engineers, 39(3), 433-464.

[12] Ridley, T. M., \& Tresidder, J. O. (1970). The London transportation study and beyond. Regional Studies, 4(1), 63-71.

[13] Fisu, A. A. (2018). Analisis Kebutuhan Fasilitas Sisi Laut Pelabuhan terminal Khusus PLTGU Lombok. PENA TEKNIK: Jurnal IImiah IImuilmu Teknik, 3(2), 197-206.

[14] Humang, W. P., \& Amrin, A. (2018). PENINGKATAN AKSES JALAN UNTUK MENUNJANG DISTRIBUSI HASIL PRODUKSI KOTA 
TERPADU MANDIRI (KTM) AIR TERANG KABUPATEN BUOL. PENA TEKNIK: Jurnal IImiah IImu-IImu Teknik, 1(2), 111-124.

[15] Humang, W. P., \& Zulfadly, A. Z. A. (2016). Analisis Keterpaduan Moda Transportasi Angkutan Penyeberangan Dengan Jalan Raya di Pelabuhan Bajoe Kab. Bone. PENA TEKNIK: Jurnal IImiah IImu-IImu Teknik, 1(1), 27-38.

[16] Fisu, A. A. (2016). Analisis dan Konsep Perencanaan Kawasan Pelabuhan Kota Penajam Sebagai Pintu Gerbang Kab. Penajam Paser Utara kalimantan Timur. PENA TEKNIK: Jurnal IImiah IImuIImu Teknik, 1(2), 125-136.

[17] Fuller, D., Sahlqvist, S., Cummins, S., \& Ogilvie, D. (2012). The impact of public transportation strikes on use of a bicycle share program in London: Interrupted time series design. Preventive medicine, 54(1), 74-76.

[18] Marzaman, L. U., Hafid, Z. A., Fisu, A. A., \& Nurhijrah, N. (2019). PLACE MAKING WORKSHOP BATUPASI SUB DISTRICT PALOPO CITY. To Maega: Jurnal Pengabdian Masyarakat, 2(1), 1-8.

[19] Hidayat, A., \& Fisu, A. A. (2020). Konsep Arsitektur Panti Rehabilitasi Ketergantungan Narkotika \& Psikotropika Di Makassar, Pendekatan Arsitektur Postmodern Historiscm. PENA TEKNIK: Jurnal IImiah IImuIImu Teknik, 5(1), 31-43.

[20] Sulaiman, L., \& Fisu, A. A. (2020). Pengaruh Campuran Terhadap Kuat Tekan Beton Agregat Recycle. Rekayasa Sipil, 14(1), 35-42.

[21] HARYONO, H. (2015). COMPARATIVE ANALYSIS OF TRANSPORTATION SYSTEM IN AMERICA, ENGLAND, AND INDONESIA. Jurnal Manajemen Bisnis Transportasi dan Logistik, 1(3), 492-509.

[22] Rowangould, D., Karner, A., \& London, J. (2016). Identifying environmental justice communities for transportation analysis. Transportation Research Part A: Policy and Practice, 88, 151-162.

[23] Fisu, A. A. (2019). Merawat Nilai Membangun Kota.

[24] Marzaman, L. U., \& Fisu, A. A. (2020). Hunian Vertikal Kontainer Buruh Pt Kima Dengan Konsep Arsitektur Humanis. PENA TEKNIK: Jurnal IImiah IImu-IImu Teknik, 5(2), 91-103.

[25] Marzaman, L. U., Hafid, Z., \& FISU, A. A. MERAJUT CERITA DI KOTA TUA (REVITALISASI KAWASAN EX PASAR LAMA PALOPO).

[26] Fisu, A. A., \& Didiharyono, D. (2020, April). Economic \& Financial Feasibility Analysis of Tarakan Fishery Industrial Estate Masterplan. In IOP Conference Series: Earth and Environmental Science (Vol. 469, No. 1, p. 012002). IOP Publishing.

[27] Natsir, R. (2018). EVALUASI KINERJA SIMPANG BERSINYAL DI KOTA PALOPO. PENA TEKNIK: Jurnal IImiah IImu-IImu Teknik, 1(1), 95-100.

[28] Fisu, A. A. (2020). Analisis Perencanaan Pengembangan Fasilitas Terminal Khusus PLTU Nagan Raya Aceh. 
[29] Marsus, B., Indriani, N. K., Darmawan, V., \& Fisu, A. A. (2020). PENGARUH PANJANG INFRASTRUKTUR JALAN TERHADAP PDRB DAN PERTUMBUHAN EKONOMI KOTA PALOPO.

[30] Fisu, A. A. (2019). 17 Tahun Kota Palopo: Kota, Manusia dan Para Penggerak.

[31] Nurhijrah, N., Fisu, A. A., Marzaman, L. U., \& Hafid, Z. KONSEP PENATAAN KAWASAN LALEBBATA SEBAGAI KAWASAN HERITAGE DI KOTA PALOPO. Jurnal Arsitektur ZONASI, 4(1).

[32] Fisu, A. A., \& Syabri, I. (2020). Demand Potential On Canal Utilization As Alternative Urban Transportation Medium In Makassar City.

[33] Marzaman, L. U., Hafid, Z., Fisu, A. A., \& Nurhijrah, N. (2021). Planning Concept of Lalebbata: Combining Heritage, Policy and Participation. PENA TEKNIK: Jurnal IImiah IImu-IImu Teknik, 6(1), 3947.

[34] Fisu, A. A. (2018). ANALISIS LOKASI PADA PERENCANAAN TERMINAL TOPOYO MAMUJU TENGAH. PENA TEKNIK: Jurnal IImiah IImu-IImu Teknik, 3(1), 1-12.

[35] FISU, A. A. STUDI AWAL LOKASI RENCANA PELABUHAN DI TELUK PRIGI KABUPATEN TRENGGALEK.

[36] Arrang, A. T. (2016). TINJAUAN KESELAMATAN LALU LINTAS TERHADAP GEOMETRIK JALAN RUAS TORAJA-PALOPO (STUDI KASUS STA. 379+ 170-STA. 383+ 300). PENA TEKNIK: Jurnal IImiah IImu-IImu Teknik, 1(2), 149-154.

[37] Fisu, A. A., Tufail, D. N., Procyoniana, S. B., \& Nugraha, R. M. (2019). TINJAUAN TRANSPORTASI PADA KAWASAN KOMERSIL (STUDI KASUS JALAN CIHAMPELAS KOTA BANDUNG). 